\title{
Experimental Study of Gas Explosions in Hydrogen Sulfide-Natural Gas-Air Mixtures
}

\author{
André Vagner Gaathaug, ${ }^{1}$ Dag Bjerketvedt, ${ }^{1}$ Knut Vaagsaether, ${ }^{1}$ and Sandra Hennie Nilsen ${ }^{2}$ \\ ${ }^{1}$ Telemark University College, Faculty of Technology, 3918 Porsgrunn, Norway \\ ${ }^{2}$ Research, Development and Innovation, Section for Health, Safety and Water Management, Statoil ASA, 3905 Porsgrunn, Norway
}

Correspondence should be addressed to André Vagner Gaathaug; andre.v.gaathaug@hit.no

Received 9 May 2014; Accepted 16 July 2014; Published 21 August 2014

Academic Editor: Constantine D. Rakopoulos

Copyright (C) 2014 André Vagner Gaathaug et al. This is an open access article distributed under the Creative Commons Attribution License, which permits unrestricted use, distribution, and reproduction in any medium, provided the original work is properly cited.

An experimental study of turbulent combustion of hydrogen sulfide $\left(\mathrm{H}_{2} \mathrm{~S}\right)$ and natural gas was performed to provide reference data for verification of CFD codes and direct comparison. Hydrogen sulfide is present in most crude oil sources, and the explosion behaviour of pure $\mathrm{H}_{2} \mathrm{~S}$ and mixtures with natural gas is important to address. The explosion behaviour was studied in a four-meterlong square pipe. The first two meters of the pipe had obstacles while the rest was smooth. Pressure transducers were used to measure the combustion in the pipe. The pure $\mathrm{H}_{2} \mathrm{~S}$ gave slightly lower explosion pressure than pure natural gas for lean-to-stoichiometric mixtures. The rich $\mathrm{H}_{2} \mathrm{~S}$ gave higher pressure than natural gas. Mixtures of $\mathrm{H}_{2} \mathrm{~S}$ and natural gas were also studied and pressure spikes were observed when $5 \%$ and $10 \% \mathrm{H}_{2} \mathrm{~S}$ were added to natural gas and also when $5 \%$ and $10 \%$ natural gas were added to $\mathrm{H}_{2} \mathrm{~S}$. The addition of $5 \% \mathrm{H}_{2} \mathrm{~S}$ to natural gas resulted in higher pressure than pure $\mathrm{H}_{2} \mathrm{~S}$ and pure natural gas. The $5 \%$ mixture gave much faster combustion than pure natural gas under fuel rich conditions.

\section{Introduction}

Hydrogen sulfide $\left(\mathrm{H}_{2} \mathrm{~S}\right)$ may be present in various concentrations in crude oil, natural gas, and biogas; an understanding of its effects is necessary since hydrogen sulfide is a toxic, flammable, and corrosive substance. The industrial process of sulfur removal will produce a lot of sulfuric biproducts. These biproducts could be a potential hazard to factory and workers. The mixture of natural gas and hydrogen sulfide has been a safety issue in development of new oil fields recently.

Jianwen et al. [1] described three major releases of hydrogen sulfide and natural gas that caused severe accidents. To reliably calculate the hazardous consequences of a hydrogen sulphide release, knowledge of its properties is critical. Earlier work investigated detonations in hydrogen sulfide, and its laminar properties have also been studied. However, experimental data from $\mathrm{H}_{2} \mathrm{~S}$ explosions are limited. This work focuses on the turbulent combustion of hydrogen sulfide and summarizes a series of experimental investigations of explosions with $\mathrm{H}_{2} \mathrm{~S}$ mixtures. These mixtures are composed of pure $\mathrm{H}_{2} \mathrm{~S}$, artificial natural gas (NG) (10\% propane and $90 \%$ methane), and NG mixed with $\mathrm{H}_{2} \mathrm{~S}$. All tests are mixed with air and are conducted at $1 \mathrm{~atm}$ initial pressure and ambient temperature. A square pipe with repeated obstacles is used to generate turbulence and increase the flame speed in the study. The experimental results provide a reference data set for verification of CFD codes and also enable a direct comparison with natural gas for the maximum pressure. As more unconventional oil sources are developed, there will be an increasing need to accurately model the combustion of natural gas and hydrogen sulfide mixtures for risk assessment.

\section{Gas Explosions in Hydrogen Sulfide}

Glassman and Yetter [2] provide a general discussion on sulfur combustion which describes the inhibition of oxidation of hydrogen by $\mathrm{H}_{2} \mathrm{~S}$. The stoichiometric combustion of $\mathrm{H}_{2} \mathrm{~S}$ in oxygen can be written as the overall reaction

$$
2 \mathrm{H}_{2} \mathrm{~S}+3 \mathrm{O}_{2} \longrightarrow 2 \mathrm{SO}_{2}+2 \mathrm{H}_{2} \mathrm{O}
$$

In a stoichiometric and rich mixture some of the $\mathrm{SO}_{2}$ products may also react with $\mathrm{H}_{2} \mathrm{~S}$ to form solid $\mathrm{S}$ by the Claus reaction [3]

$$
2 \mathrm{H}_{2} \mathrm{~S}+\mathrm{SO}_{2} \longrightarrow 3 \mathrm{~S}+2 \mathrm{H}_{2} \mathrm{O}
$$


Alzueta et al. [4] showed that $\mathrm{SO}_{2}$ could either promote or inhibit the burning of $\mathrm{CO}$ depending on the amount of $\mathrm{SO}_{2}$ and the stoichiometry. Selim et al. [3] investigated premixed methane-air with added $\mathrm{H}_{2} \mathrm{~S}$, and they showed that combustion begins with the thermal and chemical decomposition of $\mathrm{H}_{2} \mathrm{~S}$. $\mathrm{SO}_{2}$ was also found to enhance the dimerization of $\mathrm{CH}_{3}$ radicals to form longer hydrocarbons. A chemical reaction mechanism of sulfur and hydrocarbons has been proposed by Wendt et al. [5] and Frenklach et al. [6] .

Chamberlin and Clarke [7] were early investigators of the laminar flame speed of hydrogen sulfide. Their setup was typical of the period and consisted of a tube that was $1 \mathrm{~m}$ long and $2.5 \mathrm{~cm}$ in internal diameter. The tube had a burner tip. The maximum flame speed was observed at $10 \%$ $(\phi=0.8)$ and had a value of $0.5 \mathrm{~m} / \mathrm{s}$. Also a relatively wide flammable region in $\mathrm{H}_{2} \mathrm{~S}$-air mixtures was observed. Kurz [8] used a Bunsen burner method to investigate the effect of a hydrogen sulfide additive on the flame speed of propane, and he also included the flame speed measurements for pure $\mathrm{H}_{2} \mathrm{~S}$-air. The flame speed decreased as $\mathrm{H}_{2} \mathrm{~S}$ was added to the propane, up to the maximum investigated concentration of $6 \%$. However, pure $\mathrm{H}_{2} \mathrm{~S}$ resulted in a higher flame speed than the mix. A Bunsen flame was also used by Gibbs and Calcote [9] to investigate the effect of the molecular structure on the burning velocity for different equivalence ratios. These three experimental studies of $\mathrm{H}_{2} \mathrm{~S}$ flame speeds are summarized in Figure 2. As seen, there are relatively large discrepancies between the results, and it is also worth noting that none of the results consider the flame stretch effects. This work does not involve any determination of the laminar flame properties but states that the current knowledge of hydrogen sulfide flames is inconsistent. As such it does not provide a good basis for evaluation of potential hazards as compared to other gases.

There is need for further experimental investigations into the laminar burning velocities and chemical kinetics for pure $\mathrm{H}_{2} \mathrm{~S}$ gas and $\mathrm{H}_{2} \mathrm{~S}$ mixed with hydrocarbons. These studies could provide more consistent information regarding the laminar flame properties of the fuel and chemical induction delay times. Such data would be valuable as input to modelling tools and validation of chemical reaction mechanisms. Until new knowledge has been found, one must use the methods available but beware of its limitations.

Cantera software was used to calculate the constant volume combustion pressure and the constant pressure expansion ratio by the reaction mechanism of Wendt et al. [5]. These results are given in Figure 1 and are calculated for stoichiometric fuels, with the $\mathrm{H}_{2} \mathrm{~S}$ content in NG ranging from 0 (pure natural gas) to pure $\mathrm{H}_{2} \mathrm{~S}$, using increasing additions of $\mathrm{H}_{2} \mathrm{~S}$. It is shown that the equilibrium pressure and expansion ratio are inversely proportional to the hydrogen sulfide content in the fuel. The calculations suggest that there should be lower flame speed and pressure build-up in propagating hydrogen sulphide deflagration than natural gas mixtures.

Bozek and Rowe [10] compared fuel properties from the International Electrotechnical Commision (IEC) and the National Fire Protection Association (NFPA). Both datasets show that the flammability region of hydrogen sulfide is wider

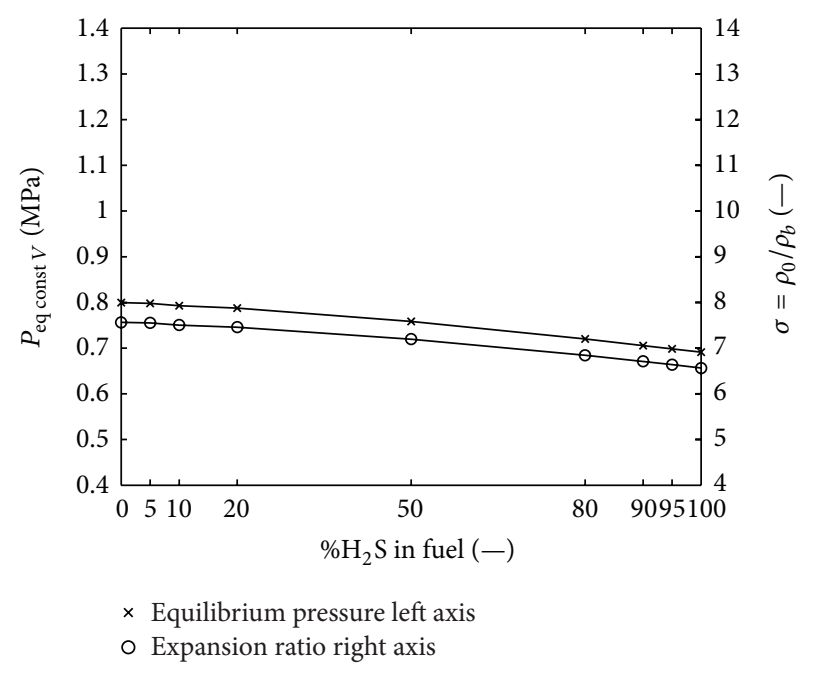

FIGURE 1: Cantera calculation. Constant volume combustion equilibrium pressure for stoichiometric fuel ranging from pure NG (left) to pure $\mathrm{H}_{2} \mathrm{~S}$ (right).

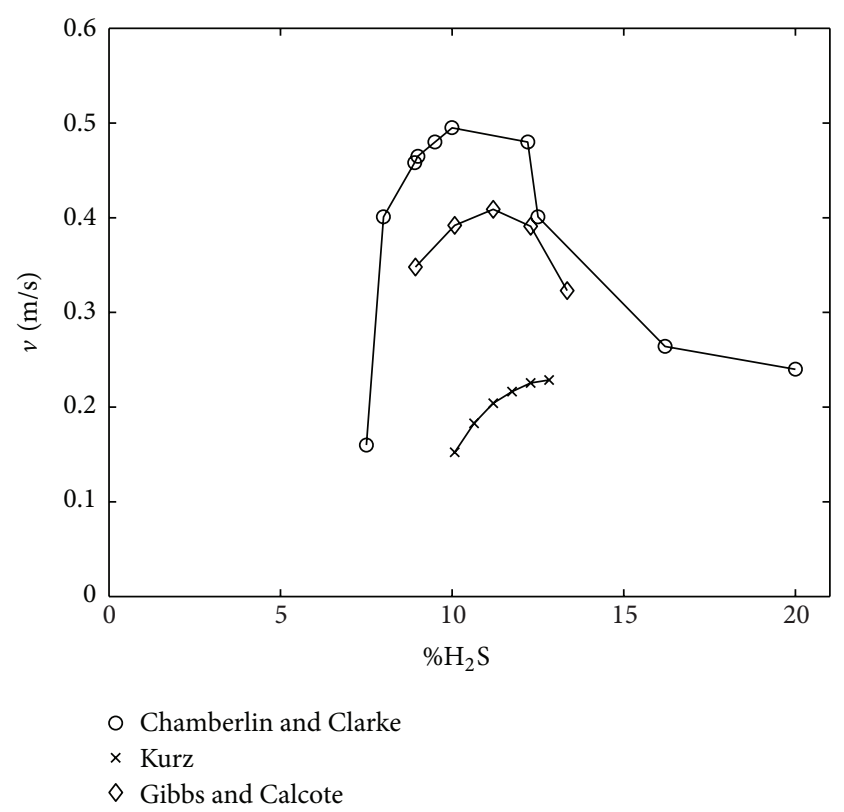

FIGURE 2: Flame speed of $\mathrm{H}_{2} \mathrm{~S}$-air mixtures at different concentrations.

than that of methane and pentane. Pahl and Holtappels [11] at the BAM Federal Institute for Materials Research and Testing investigated the explosion limits of $\mathrm{H}_{2} \mathrm{~S}$ and air in mixtures with $\mathrm{N}_{2}$ and $\mathrm{CO}_{2}$. They found the upper and lower explosion limits to be $49.8 \%$ and $3.9 \%$, respectively. When $\mathrm{CO}_{2}$ or $\mathrm{N}_{2}$ was added to the mixture, the measured explosion limits were higher than those found in an earlier work by Coward and Jones [12].

The minimum experimental safe gap MESG for hydrogen sulfide is lower than that for methane and pentane, which indicates the reactivity of the fuel. NFPA 68 Guide for Venting 
of Deflagrations (2002) provides data for the deflagration index and shows that it is higher for methane than for $\mathrm{H}_{2} \mathrm{~S}$.

Moen and coworkers [13-17] investigated flame acceleration and detonations in $\mathrm{H}_{2} \mathrm{~S}$ mixtures. The detonation cell size of hydrogen sulfide detonations was $100 \mathrm{~mm}$, while those of methane and propane were $280 \mathrm{~mm}$ and $69 \mathrm{~mm}$, respectively. This indicates that $\mathrm{H}_{2} \mathrm{~S}$ mixtures detonate easier than methane. The deflagration to detonation transition (DDT) of $\mathrm{H}_{2} \mathrm{~S}$ mixtures has not been widely investigated. Moen et al. [16] investigated the flame acceleration of $\mathrm{H}_{2} \mathrm{~S}$ air mixtures in a $1.8 \mathrm{~m}$ by $1.8 \mathrm{~m}$ cross-section and $15.5 \mathrm{~m}$ long square pipe, with obstacles made of steel pipes with diameters $500 \mathrm{~mm}$ and $220 \mathrm{~mm}$. They compared the results to those using acetylene-air mixtures. For the hydrogen sulfide experiments they recorded overpressures of only 20 to $50 \mathrm{mbar}$ and flame speeds from 36 to $81 \mathrm{~m} / \mathrm{s}$. In a comparison to acetylene they suggested that the $\mathrm{H}_{2} \mathrm{~S}$-air mixtures could detonate if the scale was large enough, the ignition was strong enough, or sufficient confinement was present.

Shepherd et al. [17] and Vervisch et al. [18] studied the activation energy of hydrogen sulfide and compared it to other fuels. The resultant value was $109.67 \mathrm{~kJ} / \mathrm{mol}$ in the Shepherd study and $92 \mathrm{~kJ} / \mathrm{mol}$ in the Vervisch study. Turns [19] gave $125 \mathrm{~kJ} / \mathrm{mol}$ activation energy for propane and $125 \mathrm{~kJ} /$ $\mathrm{mol}$ or $202 \mathrm{~kJ} / \mathrm{mol}$ for methane.

\section{Experimental Setup}

The experimental setup used in this work was made from a stainless steel square pipe with inner dimensions of $84 \mathrm{~mm}$. Four parts were bolted together and sealed to make an airtight compartment. Figure 4 shows a schematic of the four parts with their dimensions, obstacle spacing, and pressure transducer positions. Figure 3 shows a picture and Figure 5 shows a sketch of the assembled setup. The experimental setup was chosen to facilitate strong flame acceleration in the beginning and enough spacing in section 2 to possibly get local volume explosions or DDT. The experimental setup was tested also for propane, methane.

The pressures were recorded with two Kistler 7001 (Ch 1 and $\mathrm{Ch} \mathrm{2}$ ) and four Kistler 603b (Ch 3 to Ch 6) piezoelectric transducers (Figure 2) and an oscilloscope recording at $1 \mathrm{MHz}$. The ignition system was a center-mounted $10 \mathrm{kV}$ spark at the end flange of section 1 . At $10 \mathrm{~cm}$ from the end of section 4, one obstacle was installed not only to add strength but also to reflect any shock waves and achieve DDT (if possible) at the end obstacle. DDT located at the end flange is undesirable since it would cause strain on the bolts and filling system.

The fuel-air mixture was made by evacuating air from the square pipe and filling it with fuel. All tests were done with $1 \mathrm{~atm}$ initial pressure and ambient temperature. A circulation pump was used to circulate and mix the gas through the system. The setup was placed with the obstacles in vertical alignment. This prevented the fuel from being "trapped" in the pockets between the obstacles at the top and bottom of the pipe. The pump and piping was isolated from the setup before ignition.

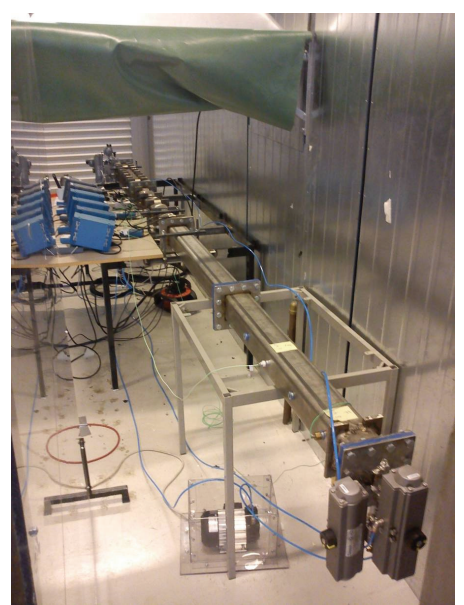

FIGURE 3: Picture of the experimental setup.

Special consideration was made regarding the toxicity of hydrogen sulfide and the sulphur dioxide combustion product. A coal filter with special coated coal was installed at the purge of the square pipe to remove sulfuric components from the gas. No $\mathrm{H}_{2} \mathrm{~S}$ was measured at the outlet of the ventilation system.

This work was part of a larger study to compare $\mathrm{H}_{2} \mathrm{~S}$ and natural gas mixtures to other more determined fuels. The fuels were acetylene, hydrogen, propane, methane, synthetic natural gas, and $\mathrm{H}_{2} \mathrm{~S}$. All fuels were mixed with air. Four different combustion regimes were observed in the study.

To illustrate these explosion regimes, the pressure records are plotted in a diagram showing time along the $x$-axis and pressure plus the positions of the pressure transducers along the $y$-axis. This type of diagram gives a good display of the trajectory of the pressure waves, shock waves, and detonation waves in a gas explosion. Figure 6 shows these four different explosion regimes in these types of diagrams:

(i) slow flame propagation and no shock waves formed in front of the flame, which is well known as a slow flame regime;

(ii) fast flame propagation (regime) and shock wave formed but no strong local explosion due to reflection of the shock at the end of the pipe;

(iii) fast flame propagation and shock wave with local explosion and transition to detonation due to reflection of the shock wave at the end of the pipe;

(iv) fast flame propagation and transition to detonation in obstructed area or close to the exit of the obstructed part of the pipe.

Only slow and fast flames were observed in the experiments reported in this paper, but the other regimes are given to provide a qualitative justification of the assumed flame propagation.

Since there is no visual recording of the flame fronts, it is only assumed that the deflagration was similar to other reported works in a very similar setup. Details of this can be found in Lee [20]. The flame fronts become stretched and 

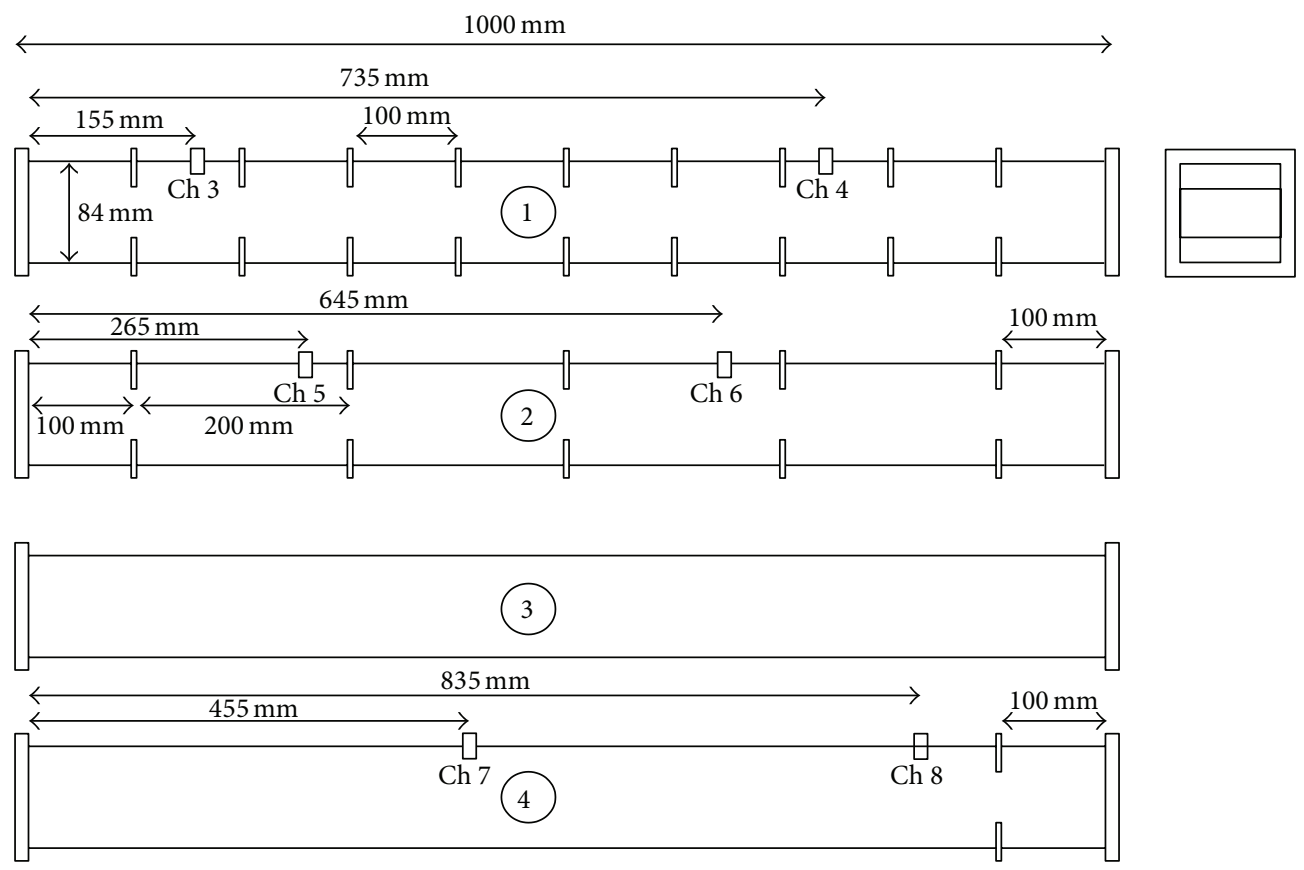

FIgURE 4: Schematic drawing of the experimental setup. $\mathrm{Ch} \#=$ pressure recording channel number.

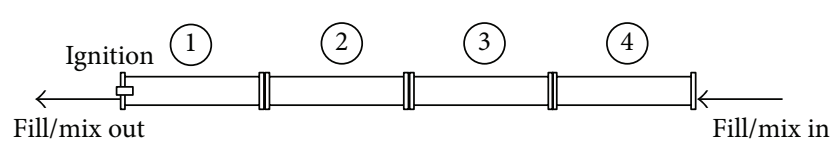

Figure 5: The experimental setup consisting of four stainless steel tube sections.

unstable as they propagate through the obstacles, and the flow through the obstacle openings can enhance the mixing at the flame front. Shock reflections at the solid obstacles are also well known to cause local explosions or DDT in sensitive gas mixtures.

\section{Results}

The fuel mixtures used in this work were pure hydrogen sulfide and fuel mixtures with artificial natural gas (premade $10 \%$ propane and $90 \%$ methane). The experiments with pure natural gas (NG) and pure $\mathrm{H}_{2} \mathrm{~S}$ in air are presented first to provide a basis for comparison. Next, results from pure $\mathrm{H}_{2} \mathrm{~S}$ are presented, and last the mixtures of $\mathrm{H}_{2} \mathrm{~S}$ and $\mathrm{NG}$ in air are presented.

The experimental matrix in Table 1 shows the gases, concentrations, and equivalence ratios.

4.1. Natural Gas. As reference experiments, tests were conducted using artificial natural gas. The concentrations were $6.2 \%, 8.3 \%, 9.2 \%$, and $10.4 \%$ corresponding to equivalence ratios of $\phi=0.72,0.99,1.11$, and 1.27 .

Pressure records from the stoichiometric experiment are given in Figure 7. The pressure curves are offset along the vertical axis, an amount equal to the distance of the
TABLE 1: Experimental matrix.

\begin{tabular}{lccccc}
\hline Test \# & Gas 1 & Vol. \% & Gas 2 & Vol. \% & $\phi$ \\
\hline 23 & $\mathrm{NG}$ & 8.30 & & & 0.99 \\
24 & $\mathrm{NG}$ & 6.20 & & & 0.72 \\
25 & $\mathrm{NG}$ & 9.20 & & & 1.11 \\
26 & $\mathrm{NG}$ & 10.40 & & & 1.27 \\
27 & $\mathrm{H}_{2} \mathrm{~S}$ & 10.00 & & & 0.79 \\
28 & $\mathrm{H}_{2} \mathrm{~S}$ & 12.40 & & & 1.01 \\
29 & $\mathrm{H}_{2} \mathrm{~S}$ & 9.00 & & & 0.71 \\
30 & $\mathrm{H}_{2} \mathrm{~S}$ & 15.10 & & & 1.27 \\
49 & $\mathrm{H}_{2} \mathrm{~S}$ & 25.00 & & & 2.38 \\
31 & $\mathrm{H}_{2} \mathrm{~S}$ & 0.43 & $\mathrm{NG}$ & 8.08 & 1.00 \\
32 & $\mathrm{H}_{2} \mathrm{~S}$ & 0.32 & $\mathrm{NG}$ & 5.99 & 0.72 \\
33 & $\mathrm{H}_{2} \mathrm{~S}$ & 0.53 & $\mathrm{NG}$ & 9.98 & 1.26 \\
34 & $\mathrm{H}_{2} \mathrm{~S}$ & 0.86 & $\mathrm{NG}$ & 7.74 & 0.99 \\
35 & $\mathrm{H}_{2} \mathrm{~S}$ & 1.80 & $\mathrm{NG}$ & 7.20 & 1.01 \\
36 & $\mathrm{H}_{2} \mathrm{~S}$ & 5.00 & $\mathrm{NG}$ & 5.00 & 1.00 \\
37 & $\mathrm{H}_{2} \mathrm{~S}$ & 8.96 & $\mathrm{NG}$ & 2.24 & 1.00 \\
39 & $\mathrm{H}_{2} \mathrm{~S}$ & 10.53 & $\mathrm{NG}$ & 1.17 & 1.00 \\
40 & $\mathrm{H}_{2} \mathrm{~S}$ & 11.40 & $\mathrm{NG}$ & 0.60 & 1.00 \\
\hline
\end{tabular}

transducer from the ignition end. After ignition the flame first propagated through the obstructed part of the pipe. This caused the flame to increase in surface area, and the flow ahead of the flame became turbulent. The turbulent flow caused the flame to accelerate and increase its reaction rate. This is seen in the pressure plots as the rate of pressure gradient increases. At early times a slow pressure increase was observed on channels 1 and 2, with a faster pressure rise seen on channels 3 and 4 . In the smooth section a propagating shock wave was recorded on channel 5 at $5.5 \mathrm{~ms}$. 

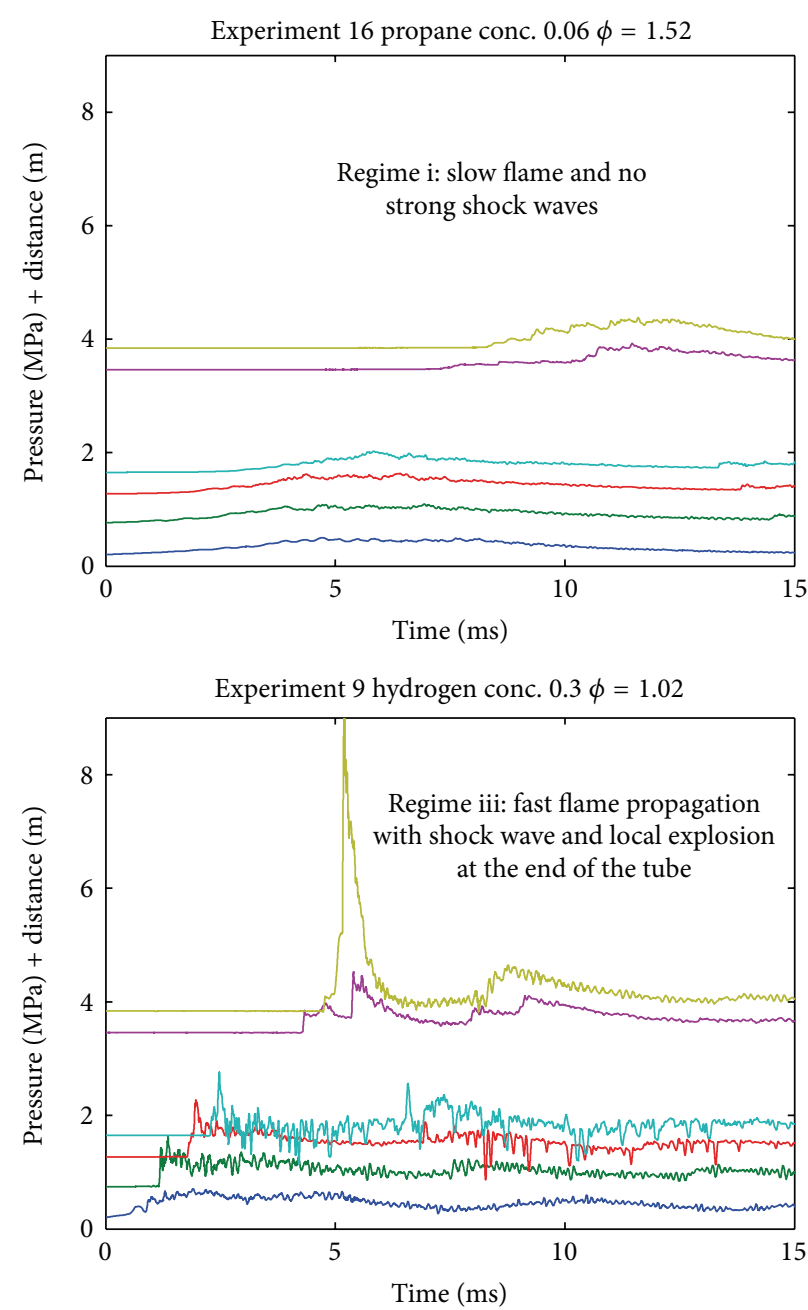

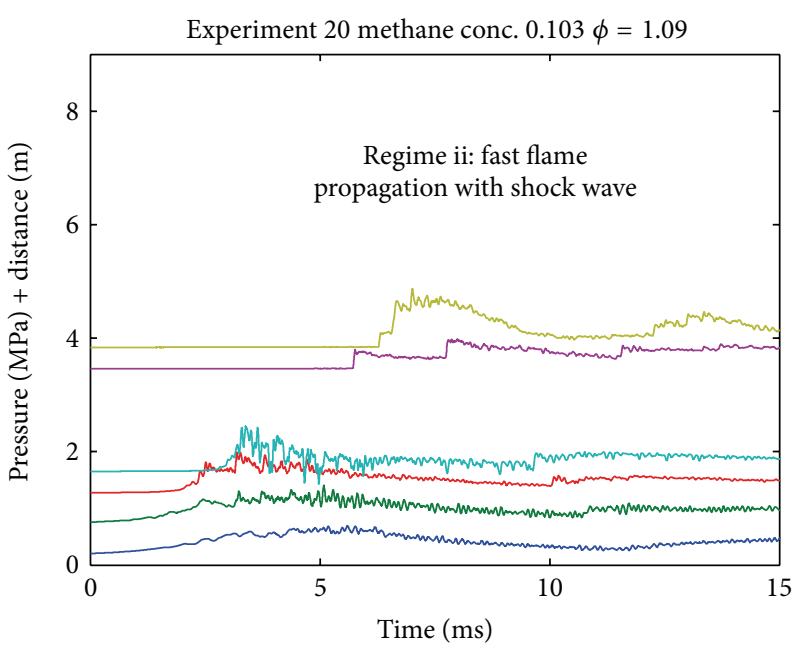

Experiment 10 hydrogen conc. $0.3 \phi=1.02$

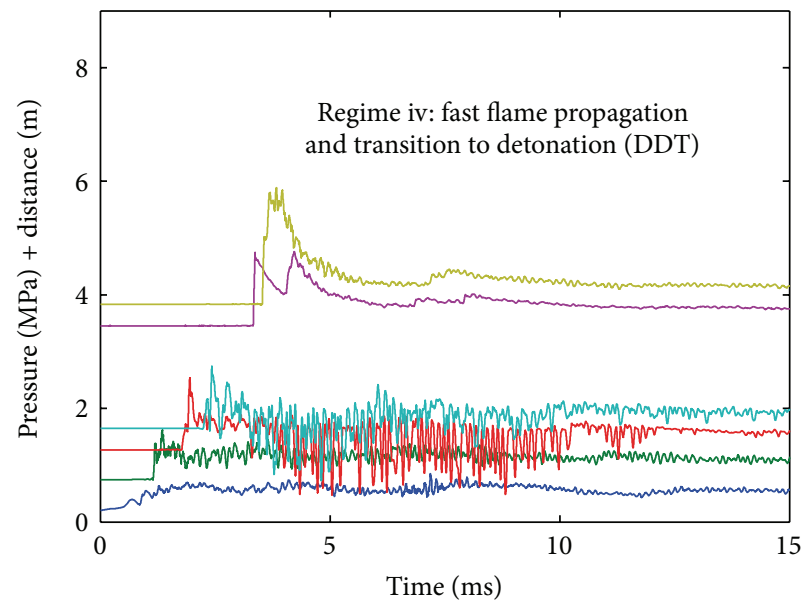

Figure 6: The four different explosion regimes.

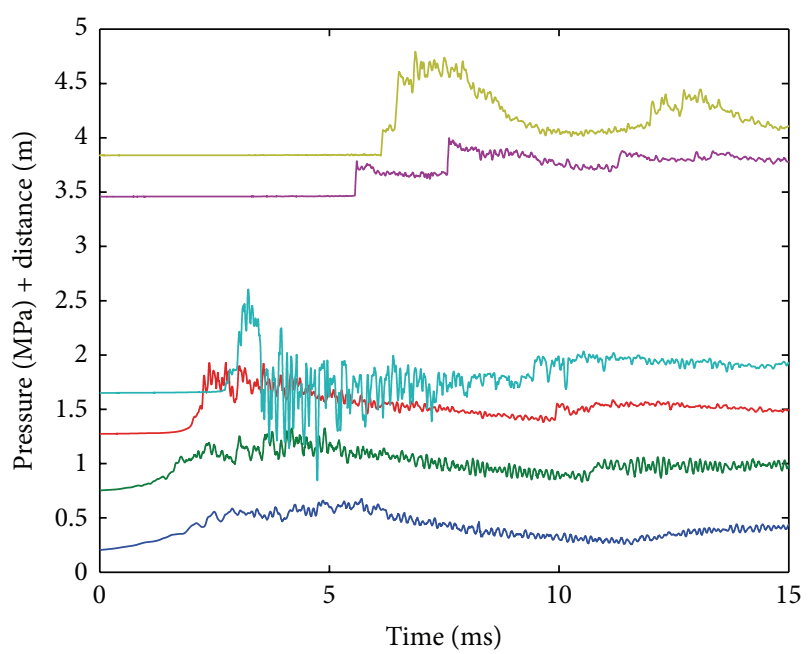

FIGURE 7: Pressure records from the stoichiometric NG-air mixture (test 23). Channels 1-6 are shown from bottom to top. The pressure levels are offset, an amount equal to the distance $(\mathrm{m})$ from the ignition end.
This was generated as the flame accelerated and the displaced flow ahead was fast enough. The shock wave was recorded on channel 6 at $6.2 \mathrm{~ms}$ and a reflection at the end obstacle was recorded at $6.5 \mathrm{~ms}$. The reflected shock wave was also recorded on channel 5 at $7.5 \mathrm{~ms}$ as it propagated backwards toward the ignition end. Further details on flame acceleration in obstructed pipes can be found in Ciccarelli and Dorofeev [21].

A comparison plot from the natural gas experiments with different fuel concentrations is given in Figure 8. The pressure is read on the left vertical axis and the equivalence ratio is shown on the right vertical axis. The horizontal axis shows the time. The leanest experiment $(\phi=0.72$ ), with $6.2 \%$ fuel in air, showed a pressure rise of almost $0.5 \mathrm{MPa}$ in the obstructed part of the experimental setup (channel 4) and a primary pressure wave of about $0.25 \mathrm{MPa}$ in the smooth section. The stoichiometric experiment with $8.3 \%$ fuel in air showed the fastest pressure rise and the highest pressure $(1 \mathrm{MPa})$. A $0.3 \mathrm{MPa}$ shock wave was recorded in the smooth section. For $9.2 \%$ fuel in air $(\phi=1.11)$, the pressure rise in the 

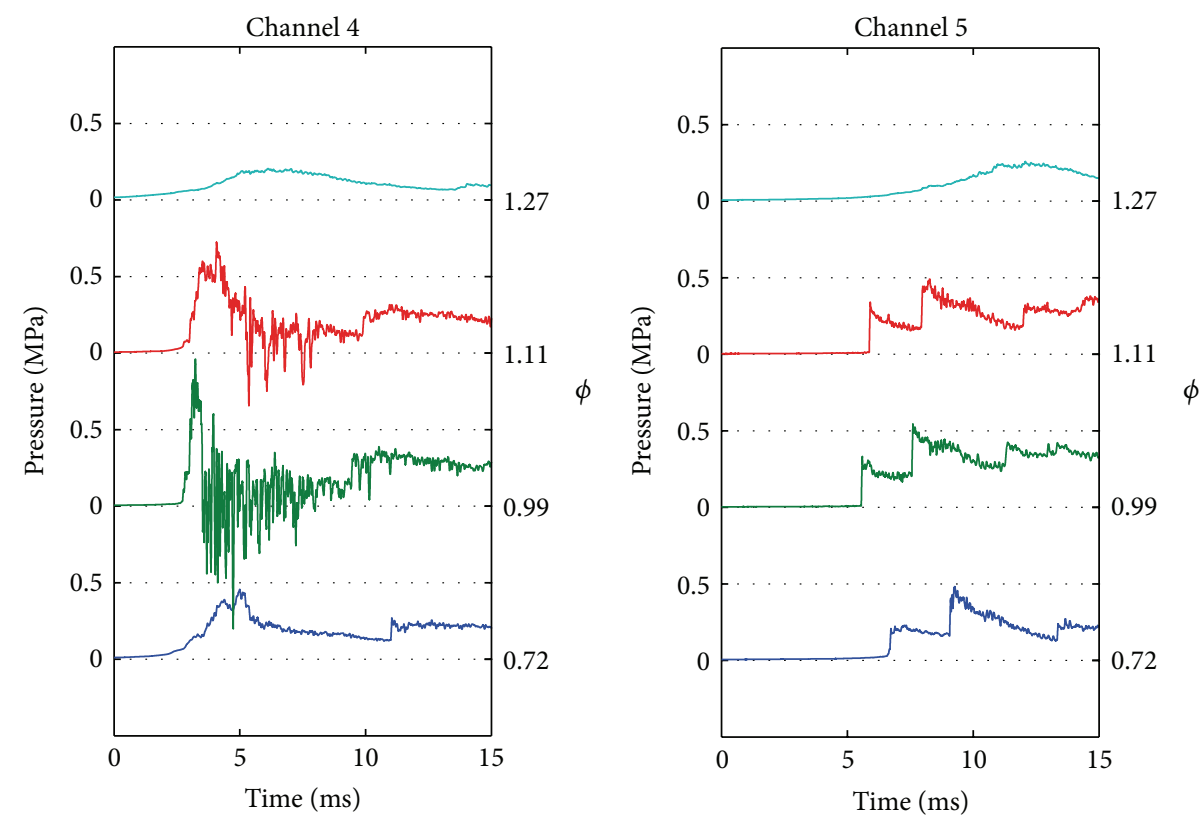

Figure 8: From bottom: tests 24, 23, 25, and 26. Comparison of pressure records from channels 4 and 5 for lean, stoichiometric, and rich NG-air mixtures. Pressure is shown on left vertical axis, while the equivalence ratio is given on the right vertical axis.

obstructed section was lower than that in the stoichiometric experiment, while the shock wave in the smooth section was almost equal. The richest experiment (10.4\% fuel in air, $\phi=$ 1.27) resulted in a slow flame and a very slow pressure rise recorded on all pressure transducers.

4.2. Hydrogen Sulfide and Air Mixtures. Results from five tests with the pure $\mathrm{H}_{2} \mathrm{~S}$-air mixture are presented. The $\mathrm{H}_{2} \mathrm{~S}$ concentration ranged from $9 \%$ to $25 \%$ (see Table 1), where $12.4 \%$ is the stoichiometric concentration. The pressure records from the stoichiometric experiment are shown in Figure 9. The overall phenomenon is similar to the stoichiometric natural gas experiment. The initial slow burning and the subsequent development to a faster turbulent flame are seen in the pressure plot. The pressure levels on channels 1 to 4 are lower than in the NG experiment, indicating that this experiment burned slower. The shock wave in the smooth section was roughly the same as in the NG experiment.

Figure 10 shows a comparison plot of the hydrogen sulfide experiments, with the pressure shown on the left vertical axis and the equivalence ratio shown on the right vertical axis. The horizontal axis shows the time. The leanest mixture was $9 \%$ $\mathrm{H}_{2} \mathrm{~S}$ in air $(\phi=0.71)$ and showed a pressure rise of about $0.3 \mathrm{MPa}$. It did not result in a shock in the smooth section of the setup. The recorded pressure wave was about $0.2 \mathrm{MPa}$, and it reflected at the end wall and obstacle. The slightly richer mixture of $10 \%(\phi=0.79)$ showed a $0.3 \mathrm{MPa}$ shock wave propagating in the smooth section of the experimental setup. In the obstructed part, $0.5 \mathrm{MPa}$ was recorded at channel 4 .

The stoichiometric mixture resulted in a $0.35 \mathrm{MPa}$ shock in the smooth section, while $0.75 \mathrm{MPa}$ was recorded in the obstructed section.

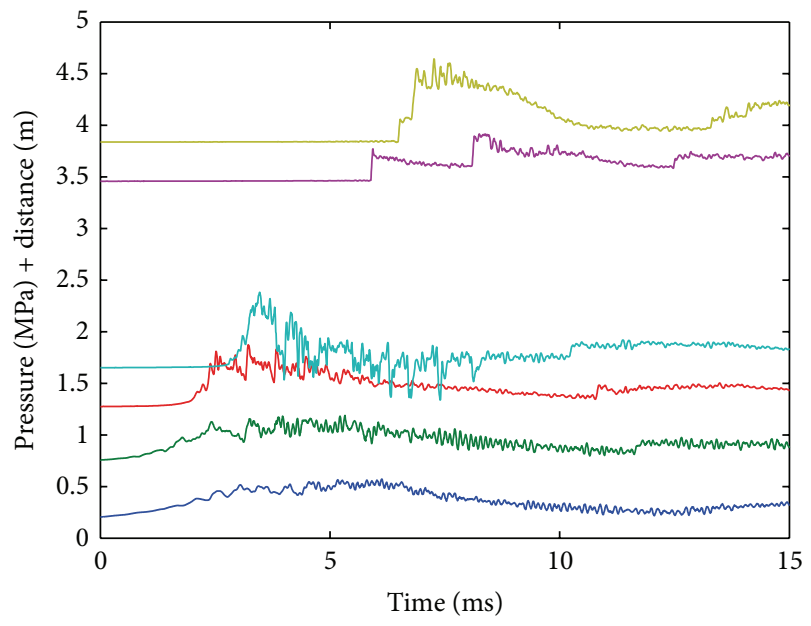

Figure 9: Pressure records from the stoichiometric $\mathrm{H}_{2} \mathrm{~S}$-air mixture (test 28). Channels 1-6 are shown from bottom to top. The pressure levels are offset, an amount equal to the distance $(\mathrm{m})$ from the ignition end.

The experiment with $\phi=1.27$ corresponding to $15.1 \%$ $\mathrm{H}_{2} \mathrm{~S}$ in air was very similar to the stoichiometric case, with only $0.05 \mathrm{MPa}$ lower pressure in the smooth section and the obstructed section. Due to the wide flammability region of $\mathrm{H}_{2} \mathrm{~S}, \phi=2.38$ was also investigated; it resulted in a very slow flame and a low pressure increase of about 0.1 MPa.

4.3. $\mathrm{H}_{2} \mathrm{~S}$-Natural Gas-Air Experiments, Results, and Discussion. Experiments were performed on a set of nine tests, with the first three containing $5 \% \mathrm{H}_{2} \mathrm{~S}$ and $95 \%$ natural gas. The equivalence ratios were $\phi=0.72, \phi=1.00$, and $\phi=1.26$. 

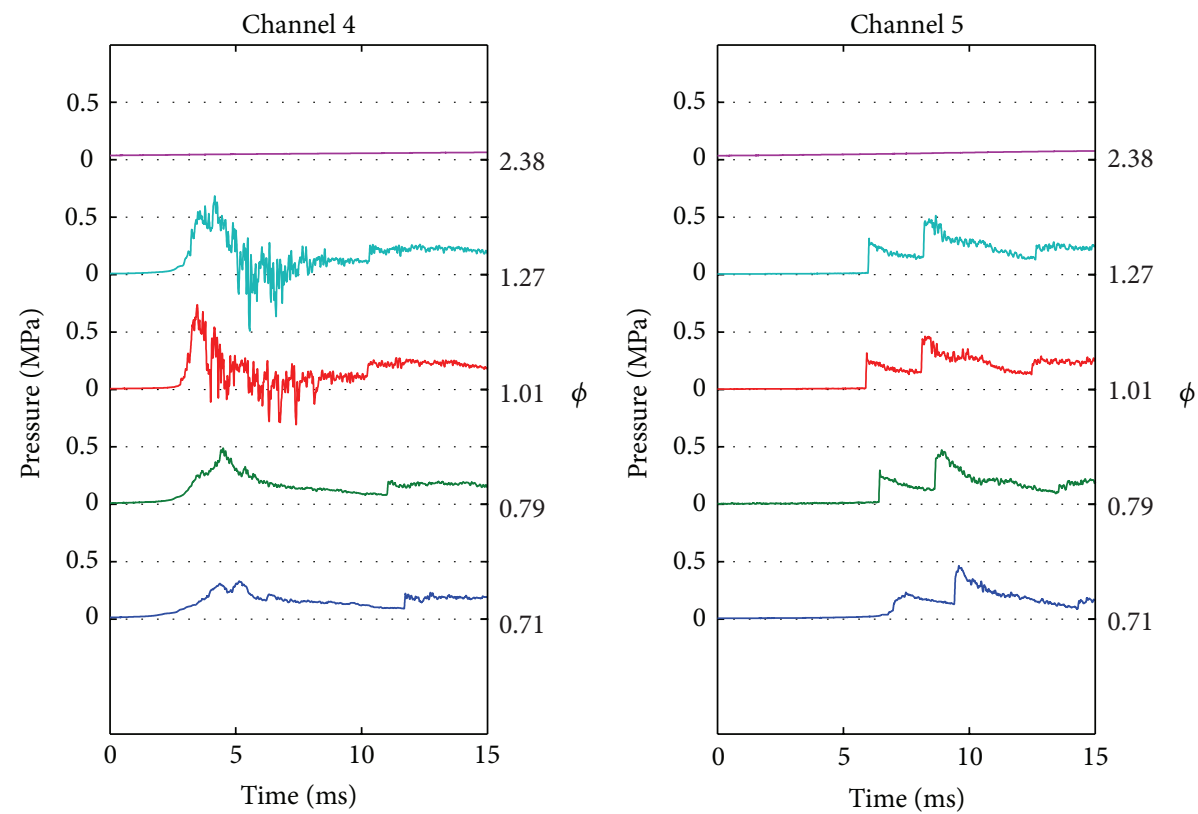

FIGURE 10: From bottom: tests 29, 27, 28, 30, and 49. Comparison of pressure records from channels 4 and 5 for lean, stoichiometric, and rich $\mathrm{H}_{2} \mathrm{~S}$-air mixtures. Pressure is shown on left vertical axis, while the equivalence ratio is given on the right vertical axis.
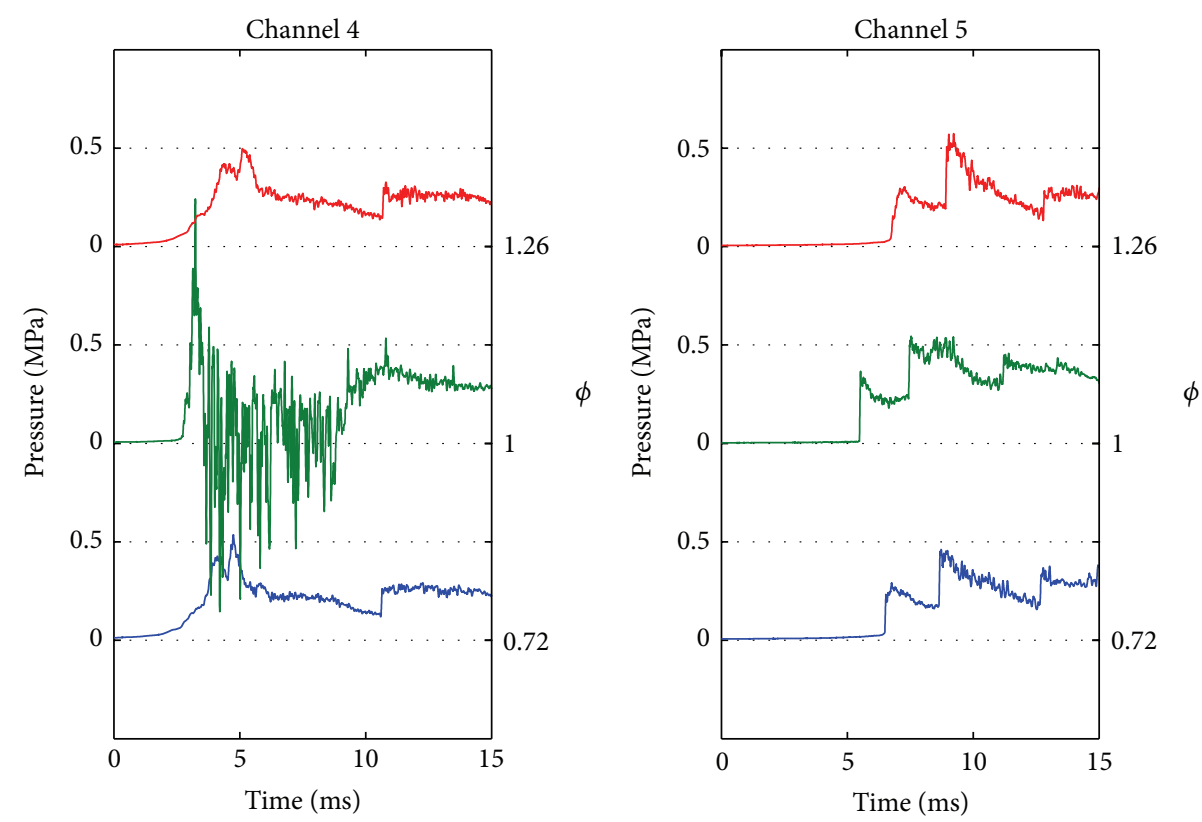

FiguRE 11: From bottom: tests 32, 31, and 33. Comparison of pressure records from channels 4 and 5. Lean, stoichiometric, and rich 5\% $\mathrm{H}_{2} \mathrm{~S} / 95 \%$ NG-air mixtures. Pressure is shown on the left vertical axis, while the equivalence ratio is given on the right vertical axis.

The following experiments were all conducted with $\phi=1$ but with increasing hydrogen sulfide content. The $\mathrm{H}_{2} \mathrm{~S}$ fractions in natural gas were $5,10,20,50,80,90$, and $95 \%$.

Figure 11 shows that, by keeping the $\mathrm{H}_{2} \mathrm{~S}$-to-NG ratio constant at 5:95 and varying the equivalence ratio, $\phi=0.72$ and $\phi=1.26$ give quite similar pressure levels: $0.5 \mathrm{MPa}$ in the obstructed part and $0.3 \mathrm{MPa}$ in the smooth section. The stoichiometric experiment resulted in the fastest pressure rise and a peak pressure of more than 1.3 MPa. A shock wave of $0.4 \mathrm{MPa}$ was recorded in the smooth section. The rich mixture $(\phi=1.26)$ resulted in strong flame acceleration, $0.5 \mathrm{MPa}$ recorded on channel 4 , and a pressure wave in the smooth section.

With the equivalence ratio kept constant at 1 and the $\mathrm{H}_{2} \mathrm{~S}$ content in the fuel varied from $0 \%$ to $100 \%$, the pressure did not change much except for some spikes, as seen in Figure 12. The pressure is shown on the left vertical axis, and the $\mathrm{H}_{2} \mathrm{~S}$ content in the fuel is shown on the right vertical axis. Time is 

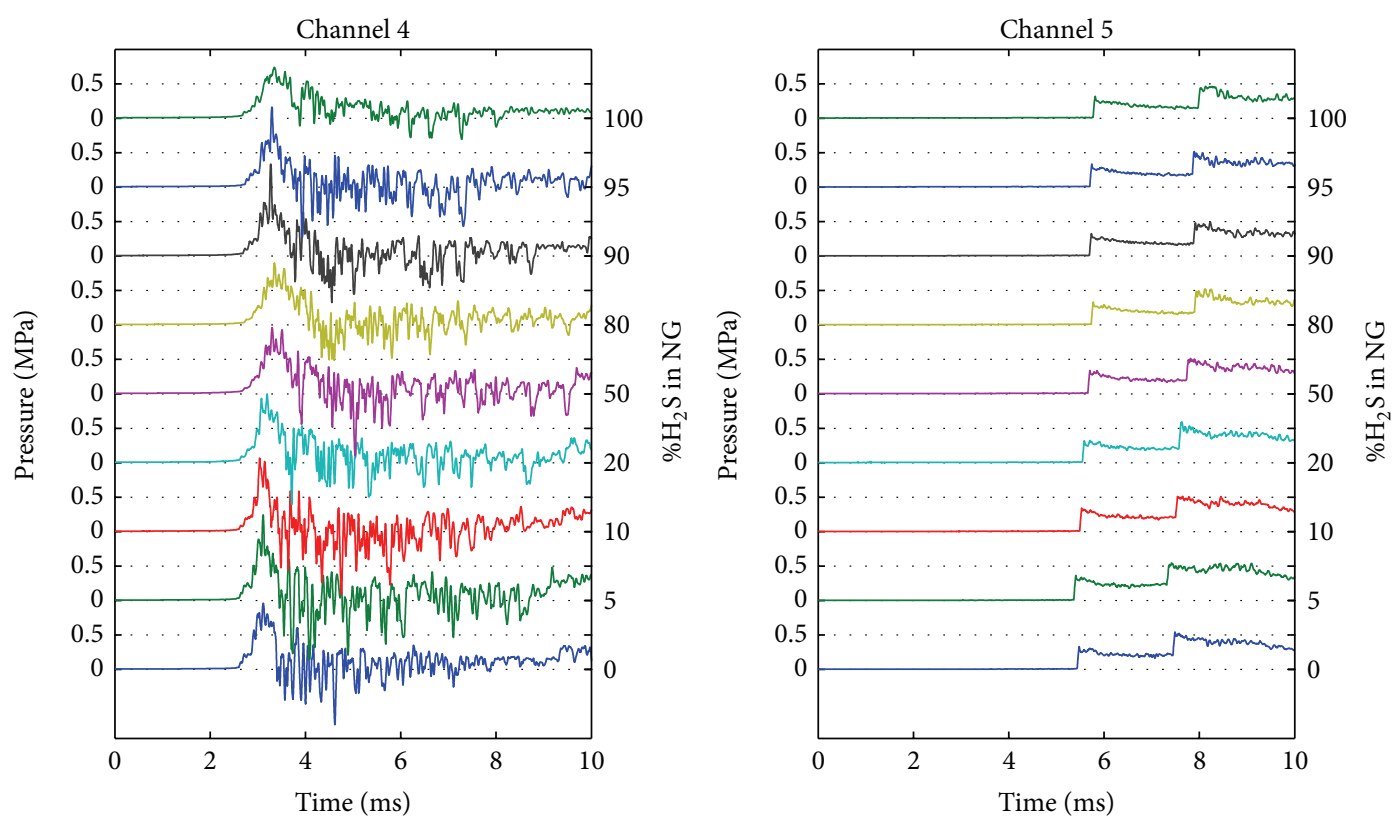

Figure 12: From bottom: tests 23, 31, 34, 35, 36, 37, 39, 40, and 28. Comparison of pressure records from channels 4 and 5 . The mixture varies from pure natural gas in the fuel (bottom) to pure $\mathrm{H}_{2} \mathrm{~S}$ in the fuel (top). All experiments are stoichiometric mixtures.

shown on the horizontal axis. The pressure in the obstructed part was recorded between 0.8 and $1 \mathrm{MPa}$, and the shock propagating in the smooth section was about 0.3 to $0.35 \mathrm{MPa}$ and reflected at $0.5 \mathrm{MPa}$.

\section{Discussion}

The experimental study for pure natural gas and air showed that the flame propagated fast when the equivalence ratio was lower than 1.27, producing strong deflagrations in the experimental setup. The pressure results showed that the rate of energy release increased as the flame propagated through the square pipe. The richest natural gas mixture investigated was $\phi=1.27$, and that mixture resulted in a slow pressure rise believed to be due to a slow burning velocity of the flame.

The explosion pressures for lean $\mathrm{H}_{2} \mathrm{~S}$-air were slightly lower than the pressures for lean NG-air. The lower explosion pressures were to some extent a result of the lower expansion ratio of the $\mathrm{H}_{2} \mathrm{~S}$-air flame compared with the other fuels. The expansion ratio $\left(\sigma=\rho_{u} / \rho_{b}\right)$ of $\mathrm{H}_{2} \mathrm{~S}$ is about 6.6 while it is 7.6 for NG. This results in a lower flame speed, less turbulence, and, therefore, a lower pressure rise.

By comparing the $\mathrm{H}_{2} \mathrm{~S}$-air mixtures with mixtures of natural gas and air, as shown in Figure 10 and Figure 8, it was observed experimentally that natural gas and $\mathrm{H}_{2} \mathrm{~S}$ result in a fast flame for $\phi=0.72$. On the rich side $(\phi=1.27)$, the hydrogen sulfide accelerated as a fast flame while the natural gas was slow. This was expected due to the wider flammability region of $\mathrm{H}_{2} \mathrm{~S}[10]$ compared with NG.

The experiments with stoichiometric $\mathrm{H}_{2} \mathrm{~S}-\mathrm{NG}$-air showed that the flame in the experimental setup produced strong deflagrations with high pressures in the obstructed part of the experimental setup. The pressures seen with

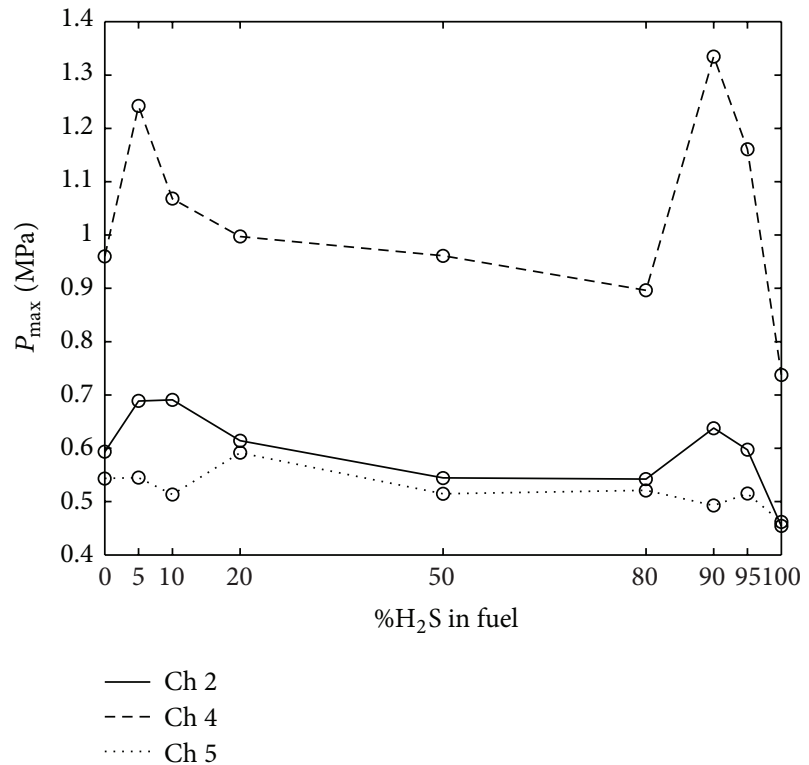

FIGURE 13: Maximum pressure from experiments. The pressure from channels 2,4 , and 5 for various $\mathrm{H}_{2} \mathrm{~S}$ contents in the fuel.

channel 4 in tests with $90 \%$ and $95 \% \mathrm{H}_{2} \mathrm{~S}$ in the fuel (1.35 and $1.15 \mathrm{MPa}$ ) indicate that the compression heating of the reactants caused local ignition in a hot spot.

Comparing the maximum pressure from channels 2, 4, and 5, a trend is observed in Figure 13 in which the maximum pressure decreases as the $\mathrm{H}_{2} \mathrm{~S}$ content in the fuel increases; however, the spikes are also observed when plotting the maximum pressure for three channels when the hydrogen sulfide content was varied. These spikes correspond to $90 \%$ 

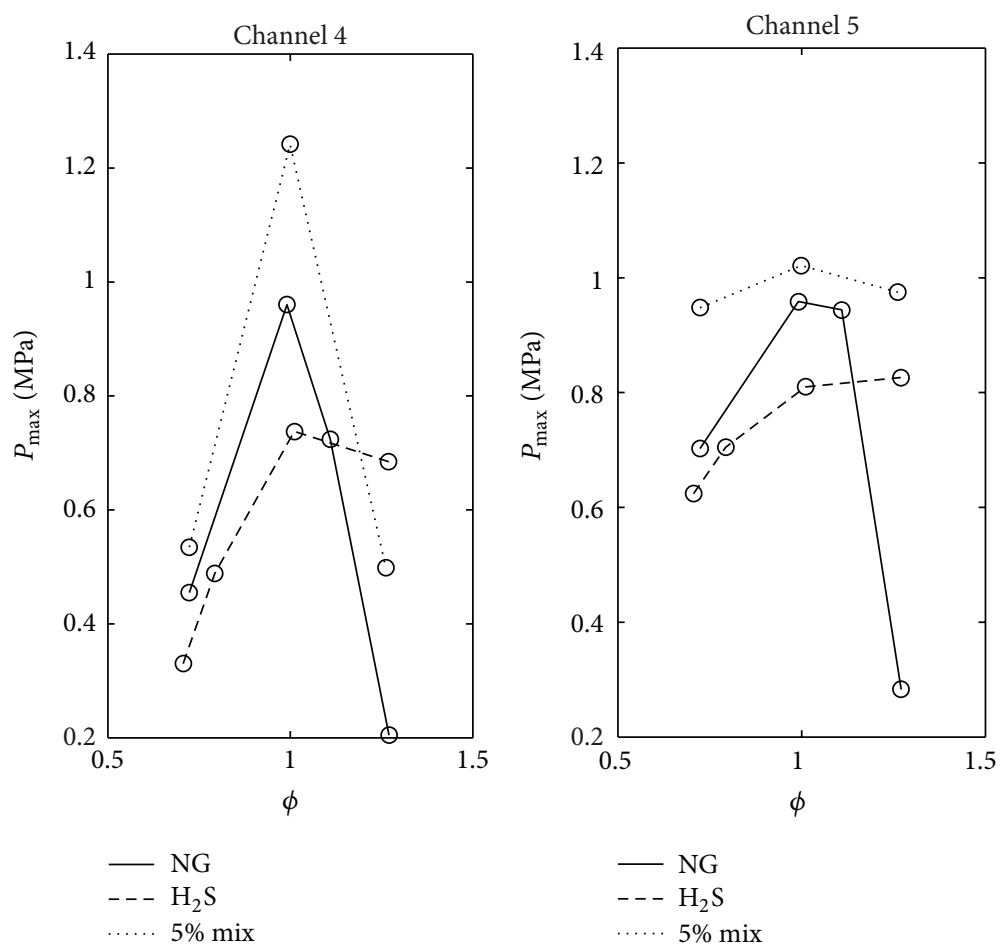

FIgURE 14: Maximum pressure for different equivalence ratios, for pure NG, pure $\mathrm{H}_{2} \mathrm{~S}$, and $5 \% \mathrm{H}_{2} \mathrm{~S}$ in NG.

and $95 \% \mathrm{H}_{2} \mathrm{~S}$ in the fuel as well as $5 \%$ and $10 \% \mathrm{H}_{2} \mathrm{~S}$ in the fuel.

Compared to the constant volume and constant pressure calculations in Figure 1 it is clear that the pressure spikes originate from different phenomena. One possible explanation could be a more sensitive mixture when small amounts of $\mathrm{H}_{2} \mathrm{~S}$ are added to natural gas or the opposite. A reduction in chemical induction delay time could lead to local explosions in heated volumes of reactants. These local explosions are very hard to determine even with full view of the channel, but other studies have shown that they are more likely to occur in the obstructed part rather than in the unobstructed parts (Lee [20]).

By comparing Figures 13 and 1, it can be seen that the pressure on channel 4 (section with obstacles) exceeds the constant volume pressure. The equilibrium pressure and the expansion ratio do not explain the spikes seen in Figure 13.

Hot spots and local ignition are closely related to deflagration to detonation transition (DDT), which results in high pressure. No DDT was recorded in these experiments, but the pressure spikes suggest that local explosions could have occurred.

There are always uncertainties when reporting the maximum pressure, since it is measured at one position. Other spikes that may occur in other sections of the experimental setup may be missed by the transducer recording.

By keeping the $\mathrm{H}_{2} \mathrm{~S}$ content in the fuel constant and changing the equivalence ratio, differences are observed in the combustion. Figure 14 shows the maximum pressure results from the tests with $100 \% \mathrm{NG}, 100 \% \mathrm{H}_{2} \mathrm{~S}$, and $5 \% \mathrm{H}_{2} \mathrm{~S}$ in NG (mix) for different equivalence ratios.
The addition of $5 \% \mathrm{H}_{2} \mathrm{~S}$ to the natural gas makes the mixture more reactive and, therefore, results in a higher pressure than that with pure $\mathrm{NG}$ and pure $\mathrm{H}_{2} \mathrm{~S}$. Another notable effect is that the mixture becomes much more insensitive to changes in the equivalence ratio when comparing the maximum pressure from channel 5 ; that is, it produces higher pressure on both lean and rich sides compared with pure fuels.

A comparison of the pressure in the obstructed section and the smooth section with and without $5 \%$ hydrogen sulfide is shown in Figures 15 and 16. Figure 15 shows the stoichiometric case, and the two pressure records from channel 4 and the two pressure records from channel 5 have the same shape and order. This indicates a similar combustion process.

When comparing the explosion pressures with the rich cases (Figure 16), it is seen that there is a major change in the pressure recordings when comparing the same channel. The pure NG burns slowly (a), while the mixed fuel (b) burns much faster and results in a strong pressure wave in the smooth section. This is a significant change caused by the addition of relatively small amounts of hydrogen sulfide to the fuel. There is still more to investigate regarding the combustion of hydrocarbons and sulfur compounds.

These experiments are small/medium scale, and the scale effects of hydrogen sulfide and natural gas explosions are still unknown; however, the presence of hot spots and pressure spikes suggests that DDT might occur if the scale was larger. It was suggested by Moen [15] that the use of a denser obstacle field in experiments would increase the turbulence and flame speed. 

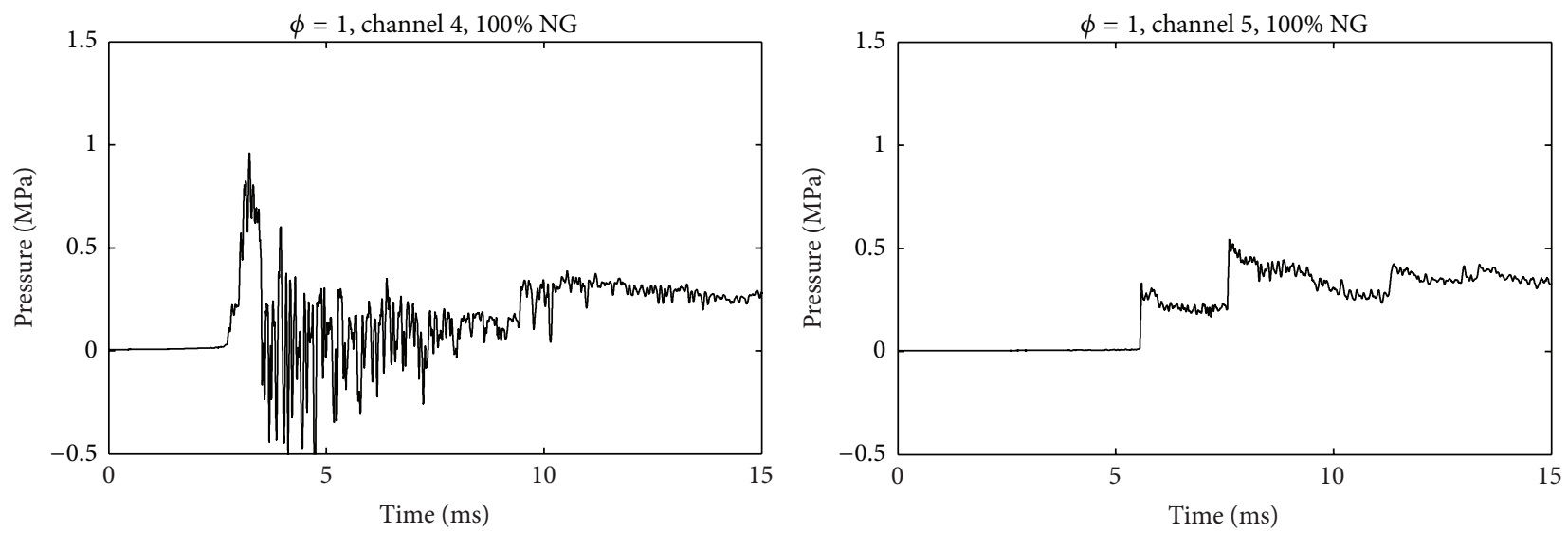

(a)
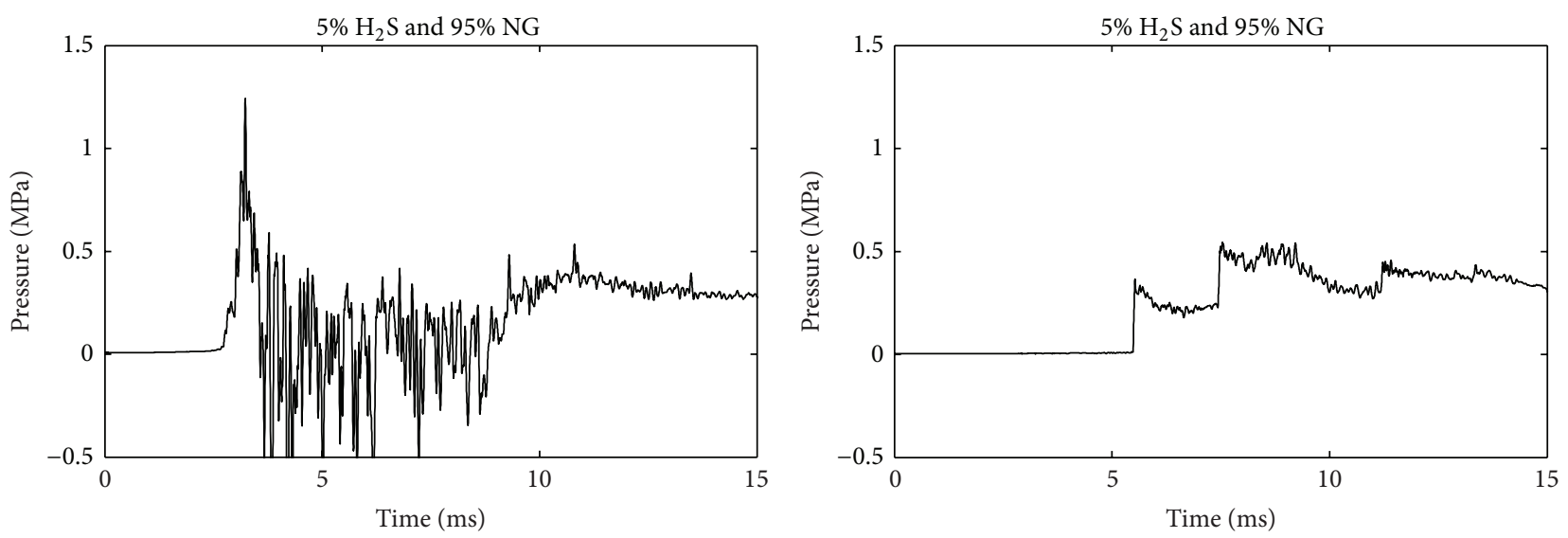

(b)

FIGURE 15: Comparison of explosion pressures for $\phi=1$ in the obstructed section (channel 4) and the smooth section (channel 5). (a) 100\% NG and (b) NG with $5 \% \mathrm{H}_{2} \mathrm{~S}$.

\section{Conclusion}

Only limited data are available in the open literature on $\mathrm{H}_{2} \mathrm{~S}$-air deflagrations and especially $\mathrm{H}_{2} \mathrm{~S}$ and natural gas mixtures. Data for explosions at conditions supporting strong flame acceleration are lacking. In the present work we have successfully performed such experiments and obtained new and unique experimental data for explosions with hydrogen sulfide and natural gas mixtures. A comparison to pure natural gas is also included.

(i) Pure fuels: hydrogen sulfide has a wide flammability region compared with methane and propane, as shown in the literature. In this study, $\mathrm{H}_{2} \mathrm{~S}$-air mixtures produced lower explosion pressures at lean-tostoichiometric compositions relative to natural gas. On the rich side, the $\mathrm{H}_{2} \mathrm{~S}$-air mixtures produced higher explosion pressures.

(ii) Fuel mixtures at $\phi=1$ : a decrease in the maximum pressure was observed when increasing amounts of hydrogen sulfide were added to the natural gas. There were, however, some maximum pressure spikes observed for $90 \%$ and $95 \% \mathrm{H}_{2} \mathrm{~S}$ in $\mathrm{NG}$, as well as for
$5 \%$ and $10 \% \mathrm{H}_{2} \mathrm{~S}$ in NG. These spikes could be a result of a local explosion of compressed reactants, but they did not develop into detonations.

(iii) Rich fuel mixtures: rich NG with 5\% hydrogen sulfide is more reactive than pure rich $\mathrm{NG}$. When $5 \% \mathrm{H}_{2} \mathrm{~S}$ was added to the NG at $\phi=1$, the result was similar to pure NG but with spikes. When the stoichiometry was changed to $\phi=1.27$ the result was a fast flame and a strong pressure wave formation in the $5 \%$ mixture, while the pure NG had a slow deflagration and a slow and low pressure rise. The 5\% mixed fuel also showed decreased sensitivity to changes in the equivalence ratio when the maximum pressures from channel 5 were investigated. These results are important to the process and petroleum industry.

For further work, it is suggested that the experimental results are compared to numerical simulations using commercial and academic software. There is also a need for a thorough study of the laminar properties of $\mathrm{H}_{2} \mathrm{~S}$-hydrocarbonair mixtures. Further experimental investigations should be conducted with higher and lower blockage ratios. Larger scale experiments could reveal the possibility of DDT in 

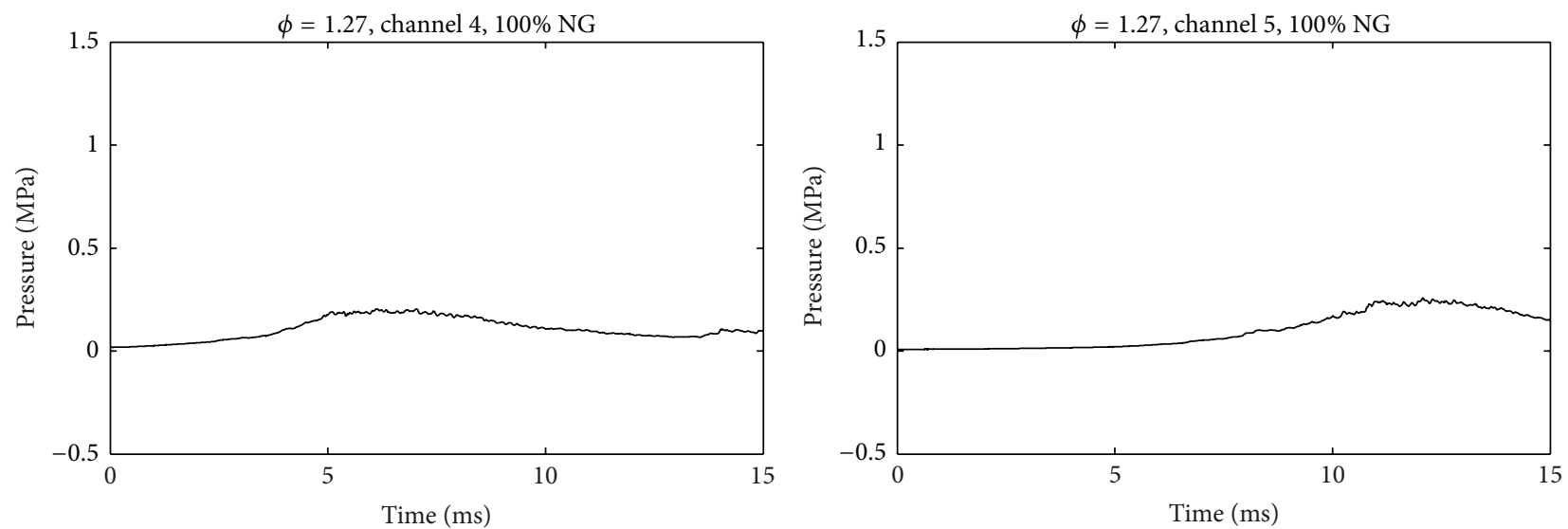

(a)
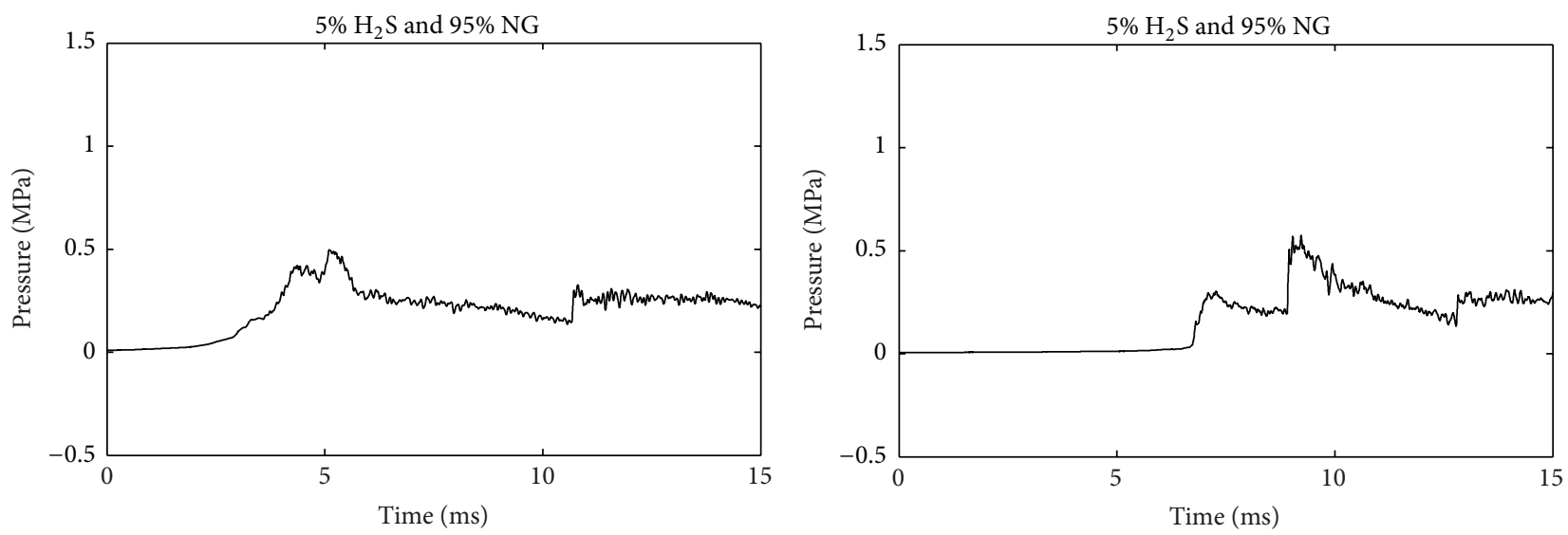

(b)

FIGURE 16: Comparison of explosion pressures for $\phi=1.27$ in the obstructed section (channel 4) and the smooth section (channel 5). (a) $100 \% \mathrm{NG}$ and (b) NG with $5 \% \mathrm{H}_{2} \mathrm{~S}$.

$\mathrm{H}_{2} \mathrm{~S}$ mixtures, and investigations of rich mixtures should be conducted to better understand the effects of added hydrogen sulfide to natural gas.

\section{Conflict of Interests}

The authors declare that there is no conflict of interests regarding the publication of this paper.

\section{Acknowledgment}

The authors gratefully acknowledge the financial support by Statoil ASA.

\section{References}

[1] Z. Jianwen, L. Da, and F. Wenxing, "Analysis of chemical disasters caused by release of hydrogen sulfide-bearing natural gas," Procedia Engineering, vol. 26, pp. 1878-1890, 2011.

[2] I. Glassman and R. Yetter, Combustion, Academic Press, 4th edition, 2008.
[3] H. Selim, A. Al Shoaibi, and A. K. Gupta, "Effect of $\mathrm{H}_{2} \mathrm{~S}$ in methane/air flames on sulfur chemistry and products speciation," Applied Energy, vol. 88, no. 8, pp. 2593-2600, 2011.

[4] M. U. Alzueta, R. Bilbao, and P. Glarborg, "Inhibition and sensitization of fuel oxidation by $\mathrm{SO}_{2}$," Combustion and Flame, vol. 127, no. 4, pp. 2234-2251, 2001.

[5] J. O. L. Wendt, E. C. Wootan, and T. L. Corley, "Postflame behavior of nitrogenous species in the presence of fuel sulfur I. Rich, moist, $\mathrm{CO} / \mathrm{Ar} / \mathrm{O}_{2}$ flames," Combustion and Flame, vol. 49, no. 1-3, pp. 261-274, 1983.

[6] M. Frenklach, J. H. Lee, J. N. White, and W. C. Gardiner Jr., "Oxidation of hydrogen sulfide," Combustion and Flame, vol. 41, pp. 1-16, 1981.

[7] D. S. Chamberlin and D. R. Clarke, "Flame speed of hydrogen sulfide," Proceedings of the Symposium on Combustion, vol. 1-2, no. C, pp. 33-35, 1948.

[8] P. F. Kurz, "Influence of hydrogen sulfide on flame speed of propane-air mixtures," Industrial \& Engineering Chemistry, vol. 45, no. 10, pp. 2361-2366, 1953.

[9] G. J. Gibbs and H. F. Calcote, "Effect of molecular structure on burning velocity," Journal of Chemical and Engineering Data, vol. 4, no. 3, pp. 226-237, 1959.

[10] A. P. Bozek and V. Rowe, "Flammable mixture analysis for hazardous area classification," in Proceedings of the 55th IEEE 
Petroleum and Chemical Industry Technical Conference (PCIC '08), pp. 1-10, September 2008.

[11] R. Pahl and K. Holtappels, "Explosions limits of $\mathrm{H}_{2} \mathrm{~S} / \mathrm{CO}_{2} /$ air and $\mathrm{H}_{2} \mathrm{~S} / \mathrm{N}_{2}$ /air," Chemical Engineering \& Technology, vol. 28, no. 7, pp. 746-749, 2005.

[12] H. Coward and G. Jones, Limits of Flammability of Gases and Vapors: Bulletin 503, US Bureau of Mines, Juneau, Alaska, USA, 1952.

[13] A. Sulmistras, I. O. Moen, and A. J. Saber, "Detonations in hydrogen sulphide-air clouds," Suffield Memorandum 1140, Defence Research Establishment Suffield, Alberta, Canada, 1985.

[14] A. J. Saber, A. Sulmistras, I. O. Moen, and P. A. Thibault, "Investigation of the explosion hazard of hydrogen sulphide (Phase I)," Research Report, Defence Research Establishment Suffield, Alberta, Canada, 1985.

[15] I. O. Moen, "Investigation of the explosion hazard of hydrogen sulphide (phase II)," Research Report, Defence Research Establishment Suffield, Alberta, Canada, 1986.

[16] I. O. Moen, A. Sulmistras, B. H. Hjertager, and J. R. Bakke, "Turbulent flame propagation and transition to detonation in large fuel-air clouds," Symposium (International) on Combustion, vol. 21, no. 1, pp. 1617-1627, 1988.

[17] J. E. Shepherd, A. Sulmistras, A. J. Saber, and I. O. Moen, "Chemical kinetics and cellular structure of detonations in hydrogen sulfide and air," in Proceedings of the 10th International Committee on the Dynamics of Explosions and Reactive Systems (ICDERS '85), p. 294, Berkeley, Calif, USA, 1985.

[18] L. Vervisch, B. Labegorre, and J. Réveillon, "Hydrogen-sulphur oxy-flame analysis and single-step flame tabulated chemistry," Fuel, vol. 83, no. 4-5, pp. 605-614, 2004.

[19] S. R. Turns, An Introduction to Combustion, McGraw-Hill, New York, NY, USA, 2nd edition, 2000.

[20] J. H. S. Lee, The Detonation Phenomena, Cambridge University Press, New York, NY, USA, 1st edition, 2008.

[21] G. Ciccarelli and S. Dorofeev, "Flame acceleration and transition to detonation in ducts," Progress in Energy and Combustion Science, vol. 34, no. 4, pp. 499-550, 2008. 

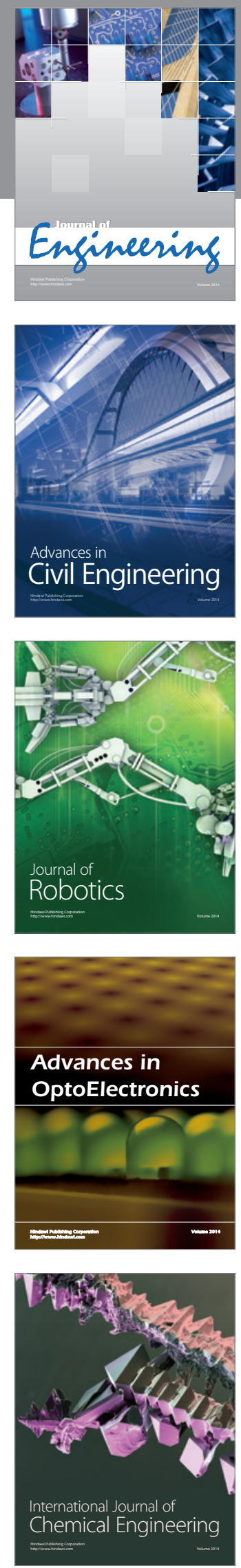

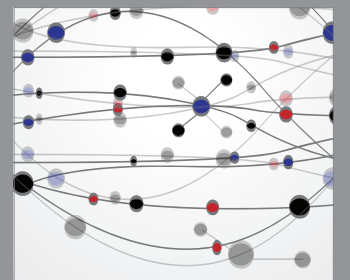

The Scientific World Journal
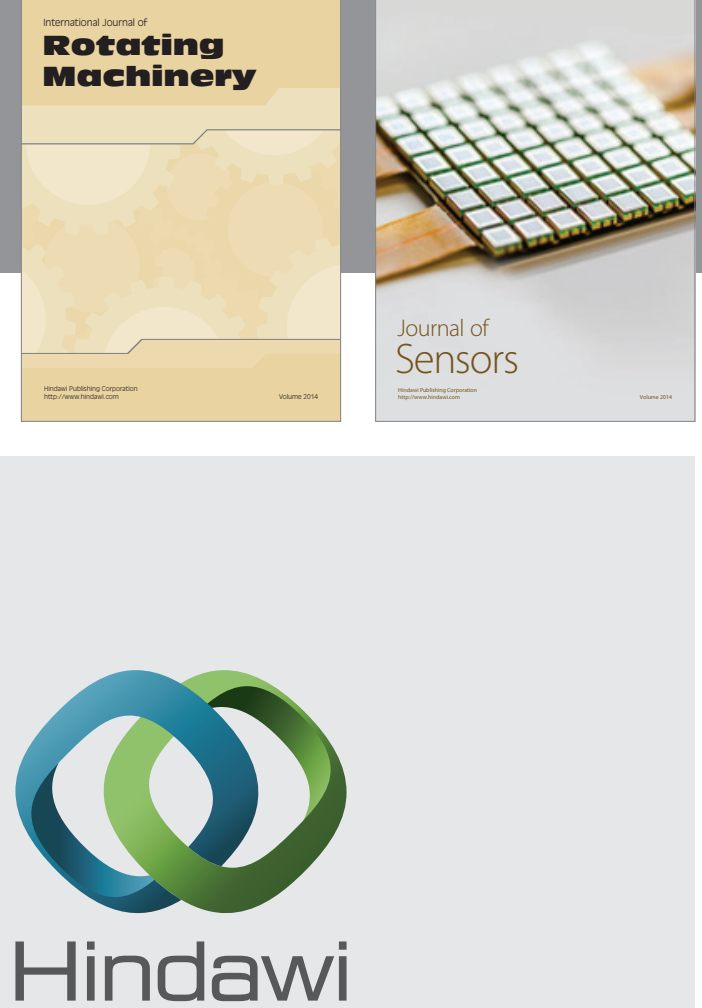

Submit your manuscripts at http://www.hindawi.com
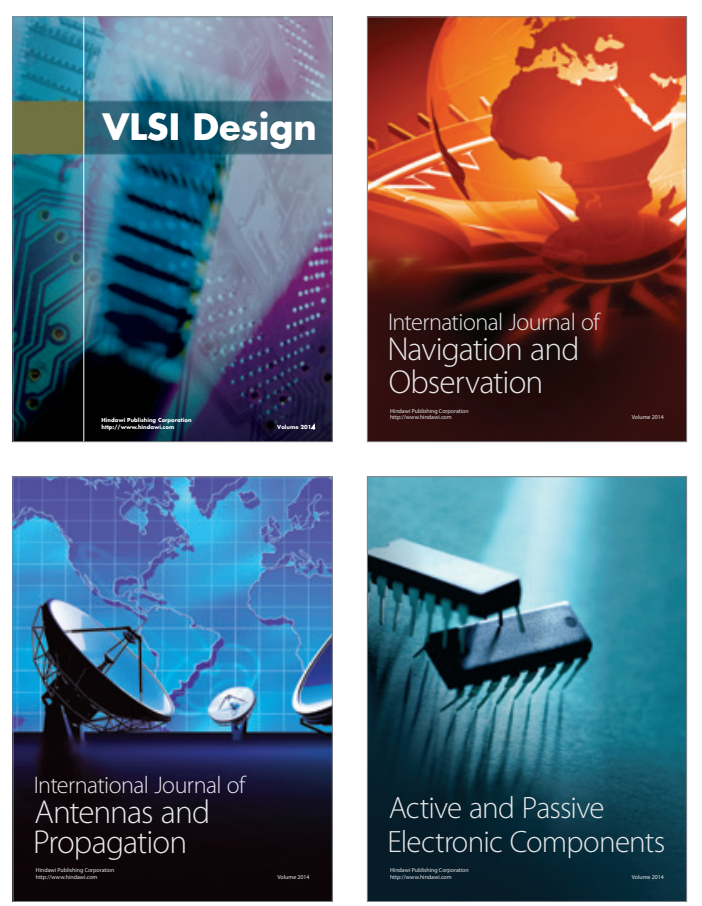
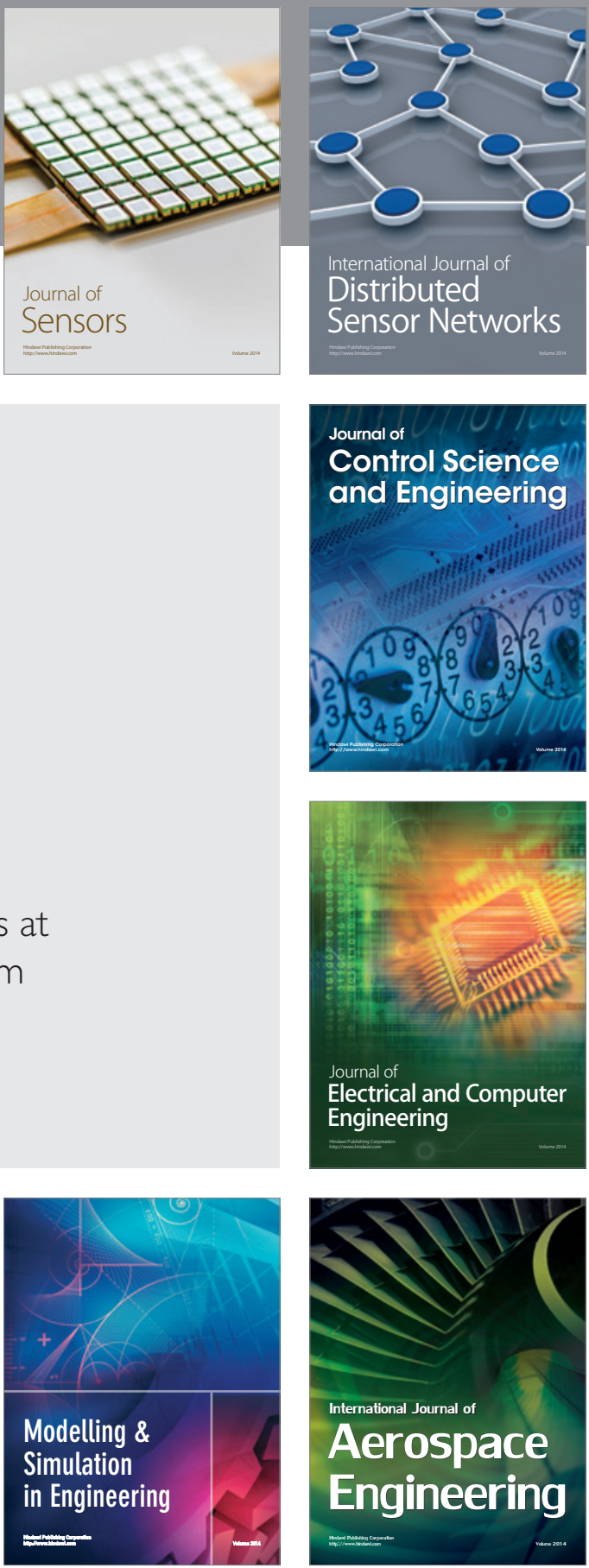

Journal of

Control Science

and Engineering
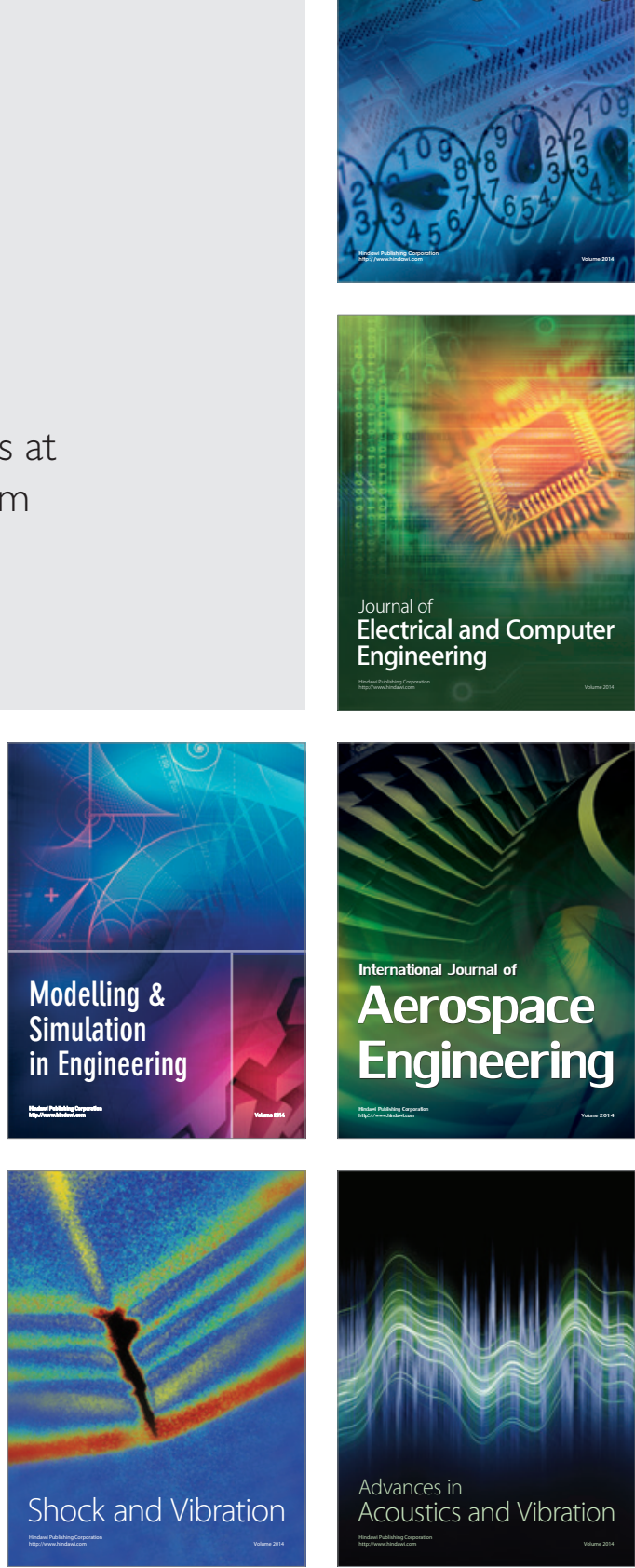